\title{
An assessment of QOL and its determining factors of post menopausal women in a rural area of West Bengal, India: A multivariate analysis
}

\author{
Dr. Sudeshna Ray ${ }^{1}$ and Professor Aparajita Dasgupta ${ }^{2}$ \\ ${ }^{1}$ Post graduate trainee, ${ }^{2}$ Professor and Head of the Department, \\ Department of Community Medicine. All India Institute of Hygiene and Public Health, Kolkata, India
}

Submission Date: 16-6-2012; Accepted Date: 26-6-2012

A B STRACT

\begin{abstract}
Objective: The aim was to assess $\mathrm{QOL}$ and its determining factors among postmenopausal women of a rural area of WestBengal in India. Methods: This cross-sectional study was conducted among 315 postmenopausal women and the data were collected using the modified menopause quality of life questionnaire of Hilditch. (Hilditch MENQOL). Results: Out of the 315 women who have been interviewed 243 (77\%) had poor quality of life. Multivariate analysis revealed that poor QOL was more among those who did not live with their own children [AOR (95\% C.I.) 4.26 (2.1-8.6)], did not undertake regular exercise, [AOR (95\% C.I.) 2.88 (1.38-6.03)], were literate [AOR (95\% C.I.) 2.5 (1.13-4.8)], were monetarily dependent on their children [AOR (95\% C.I.) 2.5 (1.32-4.88)], not living under one roof with children [AOR (95\% C.I.) $4.26(2.1-8.6)$ ] and had attained menopause $>5$ years. [AOR (95\% C.I.) 4.82 (2.47-9.41)]. Conclusion: Different stakeholders are required to mobilize the post-menopausal women through IEC activities to cope up with the stress of the post-menopausal phase and acquire a better quality of life beyond their reproductive age.
\end{abstract}

Keywords: Post-Menopausal Women, Quality of Life, Determinants of QOL, Multivariate analysis

\section{INTRODUCTION}

One of the goals of health services for all of the people in the $21^{\text {st }}$ century is to improve quality-of-life. By WHO definition, quality-of-life is the individual's perception of her status in life according to the cultural and value systems the person lives in, considering his goals, expectations, standards and concerns. ${ }^{1}$ It is not equal to the term 'health status', 'mental status' and 'well-being', it is rather a multidimensional concept incorporating the individual's perception of several domains of life giving a holistic view of one's well being.

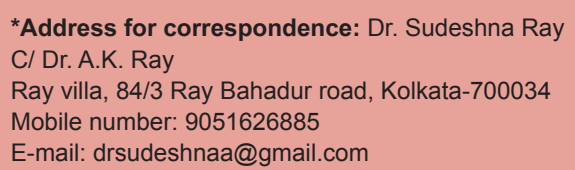

DOI: 10.5530/ijmedph.2.4.3
Women outlive men in almost all societies. They comprise $55 \%$ among those above 60 years and $65 \%$ of those above 80 years. $^{2}$ Being old and being women, they face the burden of social isolation and discrimination because they face cumulative inequalities throughout their lives from womb to tomb. With the increasing life expectancy a woman spends little less than half of her life in menopause. Concurrent, psychological, physical, vasomotor and sexual changes occurring in the postmenopausal period may disturb a woman's quality of life. Also, the quality of life of a woman in the post-menopausal age group are influenced by socio-cultural and behavioral factors compounded by their health related perceptions and health seeking behavior. Post-menopausal symptoms give rise to social consequences like the disruption of women's domestic activities and economic role and damage to psychological and emotional well-being which ultimately affect their quality of life. Most of these dimensions are extensively studied in women of reproductive age group. 
Among postmenopausal women, there is an obvious dearth of research on several of these dimensions and their net impact on the quality of women's life. This is truer in underdeveloped and developing countries and it has been observed that in India concern regarding women's health have centered around concepts of safe motherhood, reproductive health and even adolescent health to some extent. ${ }^{3}$ The issue of specific problems of women just beyond the reproductive age more so in a rural area has hardly been given any priority by the policy makers of health and it actually remains an unaddressed issue. With this backdrop, a study was planned to elicit the Quality of Life and its determinants of post-menopausal women in a rural area of West Bengal, a state in the eastern region of India.

\section{METHODOLOGY}

The data presented are the results of a 6 month crosssectional, community based study of post-menopausal women of 45-60 years of age. Menopause is defined as the cessation of periods for 12 months or cessation of ovarian function resulting in permanent amenorrhea. The age of menopause was recorded as asserted by the lady herself. The universe was all postmenopausal women of age group 45-60 years of age of Singur block of Hooghly district, in rural West-Bengal, India. The subjects were selected from women aged 45 to 60 years. ${ }^{4,5}$

Women with induced menopause, simple hysterectomy, premature menopause, receiving any kind of hormone therapy, presence of medical conditions like diabetes, hypertension, cardiac disease, and thyroid disorders were not included in the study

\section{SAMPLING DESIGN}

Sample population was collected by cluster sampling design from Singur block of Hoogly District of West Bengal having 64 villages and a total population of 1,03,652. The prevalence of joint and muscular discomfort symptoms among the post-menopausal women in rural India was $60.4 \%{ }^{4}$ A sample size of about 315 was obtained by taking a precision of $10 \%$, Design-effect of 1.4. The design effect was calculated after conducting a pilot study and using the formula of design effect as D.E $=1+(\mathrm{m}-1)^{*} \rho$ where $\mathrm{m}=$ cluster size and $\mathrm{p}=$ intra cluster correlation co-efficient derived from the pilot study in the community. 35 clusters were chosen including 30 villages by probability proportionate to size technique, with 9 subjects in each cluster.

A pre-designed, pre tested schedule MENQOL was used. It contains 29 questions about quality-of-life in menopause designed by Hilditch. It was translated in the local language (Bengali) which was then backtranslated to verify content, criteria and semantic equivalence by bilingual and monolingual experts and used on the post-menopausal women of 45-60 years after obtaining informed consent from them. Of all questions in the original Hilditch questionnaire after pretesting, we selected and utilized 24 questions which were most appropriate for this study population (2 questions on vasomotor aspects, 6 questions on psychosocial aspects, 14 questions on physical aspects and 2 questions on sexual aspects). According to the scoring system of original version of MENQOL, each question should have been scored by 8 points. However, following pretesting the researcher realized that a 4 point Likert scale elicited better, clearer and more discrete response than a 8 point Likert scale. We evaluated our modified questionnaire and four-point scoring system. By recruiting a panel of experts the content validity of the modified questionnaire was approved. The experts were able to review the items and comment on whether the items covered the representative aspects of each domain. We did the pilot study with the modified questionnaire on 32 Post-menopausal women and Cronbach $\alpha$ approved the reliability of questionnaire (0.80). In this 4points Likert scoring method, each question was scored by (0 point: subject had no problem, 1 point: subject had a problem causing mild distress, 2 points: subject had a problem resulting into moderate distress, 3 points: subject had a problem that causes relatively severe distress). Hereby, scores for vasomotor aspect ranged from 0 to 6 , for psychosocial aspect from 0 to 18 , for physical aspect from 0 to 42 and for sexual aspects from 0 to 6 . The total score of quality-of-life for each participant could be from 0 (the lowest level) to 72 (the highest level) points. Lower the score better was the quality of life.

\begin{tabular}{|c|c|c|c|c|}
\hline Symptoms & Score 0 & Score 1 & Score 2 & Score 3 \\
\hline $\begin{array}{l}\text { Vasomotr Symptoms } \\
\text { 1. Hot flushes } \\
\text { 2. Night sweats }\end{array}$ & $\begin{array}{l}\text { Subject had no } \\
\text { problem. }\end{array}$ & $\begin{array}{l}\text { Subject had a } \\
\text { problem causing } \\
\text { mild distress. }\end{array}$ & $\begin{array}{l}\text { Subject had a problem } \\
\text { resulting into moderate } \\
\text { distress. }\end{array}$ & $\begin{array}{l}\text { Subject had a problem } \\
\text { that causes relatively } \\
\text { severe distress. }\end{array}$ \\
\hline
\end{tabular}




\section{Physical Symptoms}

1. Flatulence (wind)

2. Aching in muscle \& joints

3. Feeling tired or worn out

4. Difficulty sleeping

5. Aches in back of neck or head

6. Decrease in physical strength

7. Decrease in stamina

8. Feeling a lack of energy

9. Weight gain

10. Changes in appearance, texture or tone of your skin

11. feeling bloated

12. Low backache

13. Frequent urination

14. Involuntary urination when laughing or coughing

\section{Sexual Symptoms}

1. Change in your sexual Desire

2. Vaginal dryness during intercourse

Phycosocial Symptoms

1. Being dissatisfied with my personal life

2. Feeling anxious or nervous

3. Experiencing poor memory

4. Accomplishing less than I used to

5. Feeling depressed, down or blue

6 . Being impatient with other people
Subject had no problem.

\section{Subject had no} problem.

Subject had no problem.
Subject had a

problem causing mild distress.
Subject had a problem resulting into moderate distress.
Subject had a problem that causes relatively severe distress.

\section{DETERMINANTS}

1. The age of the woman could be an important determinant of her quality of life and thus age was dichotomized with the cut off being the median age 50 yrs.

2. Regarding literacy, as the study was conducted in rural India where most of the women were housewives and illiterate the education level was simply based on whether the women were literate or not.

3. To assess whether social class and economic status could be a determining factor of the QOL of a women beyond her reproductive years, PCI (Per Capita Income) was included in the analysis as a covariate after being dichotomized as > Rs 1000 and $\leq$ Rs 1000 (based on the median PCI).

4. To elicit whether duration of menopause actually affected the wellbeing of the middle aged woman: time since menopause was considered as a determinant of QOL and data was collected based on participants' recall of their menopausal age. The assumption in this regard however was: $\leq 5$ yrs since attainment of menopause is considered as a relatively lesser duration of menopausal onset and $>5 \mathrm{yrs}$ as a considerable longer duration.

5. Regular exercise Physical activity of the study population was assessed with the variable of regular exercise in the form of brisk walking for $30 \mathrm{~min}$ at least 5 days a week as this was the commonest form of exercise being affordable and undertaken by rural Indian women.
6. Harmony in family life that is perceived change in relationship with husband (deteriorated or not deteriorated) following menopause life was recorded. This is considered to be a very important dimension of QOL as it plays an important role in determining the overall satisfaction in life in case of rural women who are very much dependent on their husbands in every aspect of life.

7. Living with own children under one roof could provide considerable psychological support to the women which could have its effect on her overall quality of life. Hence this variable was taken into account. It is worthwhile to mention that the concept of parents living with children is still in vogue in rural India but due to urbanization many children leave their parents in the villages and settle in the cities to earn for their livelihood. Under these conditions it is felt that those who cannot live with their children are always under stress and a sense of being neglected.

8. Getting monetary support from children was considered to be a determinant of QOL of the study population.

9. Perception of one's own health was included based on a single question that was asked to the participants on how they feel about their own health status (scores ranged from $0-5)$. The recorded scores were $1=$ very poor, $2=$ poor, $3=$ neither good nor poor/average, $4=$ good, $5=$ very good. This perception of health status scores were dichotomized with the median score of 3 as the cut off and was recorded as Good health (score $>3$ ) and Average health (score $\leq 3)$. 


\section{STATISTICS}

Analysis was done in two phases. At first association was found out between the various domains of MENQOL, and several socio-behavioral variables. These predictors were treated as categorical with an explicitly defined category and the most advantaged group represented the reference category for all categories. Then logistic regression model was fitted to estimate predictors of poor QOL. Only significant predictors were entered in the equation through backward LR Method. All analysis was carried out using SPSS19.

\section{RESULTS}

Table 1: Distribution of study Population with poor QOL in the different domains (Vasomotor, Physical, Sexual, Psychosocial) in respect to some socio-demographic and behavioral factors $(\mathrm{N}=315)$. Throughout it was observed that the proportion of women with poor QOL was more among those who were more than 50 years, more literate, had PCI $\leq$ Rs1000, attained menopause for $\leq 5$ years, did not do exercise, had poor relationship with husband, not living with own children, not receiving monetary help from children and those who felt that they had average health status.

Table 2. - Shows the bivariate association of different socio-demographic and behavioral factors with the vasomotor, physical, sexual and psychosocial domains of menopause related quality of life. Further both bivariate and multivariate analysis was done on Quality of Life as a whole where all the 4 domains were considered together.

VASOMOTOR DOMAIN: Bivariate analysis reveals that higher score in vasomotor domain, (poor QOL) was associated with age of the woman $>50 \mathrm{yrs}$, P.C.I $\leq$ Rs 1000 , attainment of menopause for $>5 \mathrm{yrs}$, deterioration of relationship with husband after menopause, not living under the same

\begin{tabular}{|c|c|c|c|c|c|c|}
\hline \multirow[b]{2}{*}{ Variables } & \multirow[b]{2}{*}{ Number } & \multicolumn{5}{|c|}{ Domains } \\
\hline & & $\begin{array}{c}\text { Vasomotor } \\
\text { median } \\
\text { score }(I Q R) \text { : } \\
\geq 4(2-5) \\
\text { Number }(\%)\end{array}$ & $\begin{array}{c}\text { Physical } \\
\text { median } \\
\text { score }(I Q R): \\
\geq 30(24-33) \\
\text { Number }(\%)\end{array}$ & $\begin{array}{c}\text { Sexual } \\
\text { median } \\
\text { score }(I Q R) \text { : } \\
\geq 3(2-4) \\
\text { Number }(\%)\end{array}$ & $\begin{array}{c}\text { Psychosocial } \\
\text { median score } \\
\text { (IQR): } \\
\geq 8(5-15) \\
\text { Number }(\%) \\
\end{array}$ & $\begin{array}{c}\text { Total median } \\
(I Q R) \geq 45 \\
(43-47) \\
\text { Range }=40-47 \\
\text { Number }(\%)\end{array}$ \\
\hline \multicolumn{7}{|l|}{ 1. Age } \\
\hline$\leq 50$ Yrs & 108 & $48(44.4)$ & $24(22)$ & $56(51.8)$ & $74(68.5)$ & $65(60.2)$ \\
\hline$>50$ Yrs & 207 & $138(67)$ & $134(64.7)$ & $77(37)$ & $93(44.9)$ & $178(85.9)$ \\
\hline \multicolumn{7}{|c|}{ 2. Literacy level } \\
\hline Literate & 105 & $69(65.7)$ & $59(56.2)$ & $24(22.8)$ & $70(66.6)$ & $178(84.7)$ \\
\hline Illiterate & 210 & $117(55.7)$ & $98(46.7)$ & $52(75.2)$ & $100(47.6)$ & $65(61.9)$ \\
\hline \multicolumn{7}{|c|}{ 3. Per capita income (in Rupees) } \\
\hline$>1000$ & 140 & $69(49.2)$ & $59(42)$ & $68(48.5)$ & $95(67.8)$ & $84(60)$ \\
\hline$\leq 1000$ & 175 & $117(66.8)$ & $99(56.5)$ & $65(31.7)$ & $75(42.8)$ & $159(90.9)$ \\
\hline \multicolumn{7}{|c|}{ 4. Time since attaining menopause } \\
\hline$\leq 5 \mathrm{yrs}$ & 111 & $28(25)$ & $31(28)$ & $59(53.2)$ & $83(74.7)$ & $66(59.4)$ \\
\hline$>5$ yrs & 204 & $158(77.4)$ & $94(46)$ & $74(36.2)$ & $115(56.3)$ & $177(86.7)$ \\
\hline \multicolumn{7}{|c|}{$\begin{array}{l}\text { 5. Regular exercise in the form of brisk walking } \\
\text { for } 30 \text { min at least } 5 \text { days a week }\end{array}$} \\
\hline Yes & 179 & $112(62.6)$ & $57(31.8)$ & $72(40.2)$ & $100(55.9)$ & $123(68.7)$ \\
\hline No & 136 & $74(54.4))$ & $101(74.2)$ & $61(44.8)$ & $98(72.0)$ & $120(88.2)$ \\
\hline \multicolumn{7}{|c|}{$\begin{array}{l}\text { 6. Relationship with husband deteriorated after } \\
\text { Menopause }\end{array}$} \\
\hline Yes & 191 & $127(66.4)$ & $117(61.2)$ & $81(42.4)$ & $150(78.5)$ & $173(90.6)$ \\
\hline No & 124 & $59(47.5)$ & $41(33.06)$ & $52(41.9)$ & $48(38.7)$ & $70(56.5)$ \\
\hline \multicolumn{7}{|c|}{ 7. Living under one roof with own children } \\
\hline Yes & 146 & $69(47.2)$ & $83(56.8)$ & $69(47.2)$ & $73(50)$ & $90(61.6)$ \\
\hline No & 169 & $117(69.2)$ & $74(43.7)$ & $64(37.9))$ & $125(73.9)$ & $153(90.5)$ \\
\hline \multicolumn{7}{|c|}{ 8. Monetary support from children } \\
\hline No & 105 & $61(58.1)$ & $38(36.2)$ & $142(67.6)$ & $120(57)$ & $63(60)$ \\
\hline Yes & 210 & $68(32.4)$ & $120(57.2)$ & $44(42)$ & $38(36)$ & $180(85.7)$ \\
\hline \multicolumn{7}{|c|}{ 9. Perception of one's own health } \\
\hline Good & 150 & $77(51)$ & $64(42.6)$ & $77(51.3)$ & $59(39.3)$ & $99(66)$ \\
\hline Average & 165 & $109(66)$ & $94(57)$ & $56(33.9)$ & $92(55.75)$ & $144(87.2)$ \\
\hline
\end{tabular}




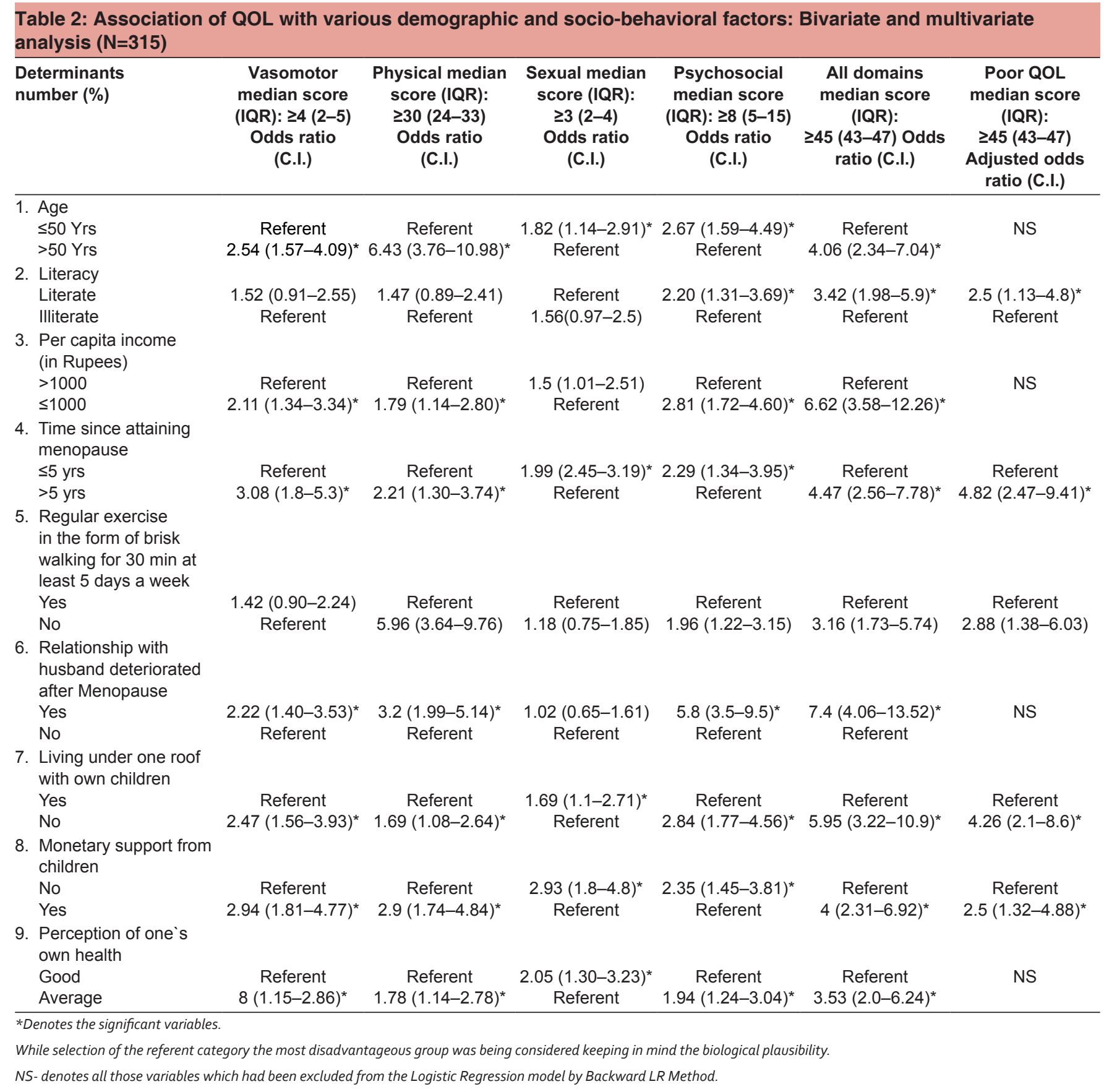

roof with children, dependent on children for monetary support and perception of one's own health as average.

PHYSICAL DOMAIN: Women who were $>50$ yrs of age, illiterate, having P.C.I $\leq$ Rs 1000 , and attained menopause for $>5$ years and did not undertake exercise in the form of brisk walking suffered from greater amount of physical symptoms. Apart from this, deterioration of relationship with husband after menopause, monetary dependency on children also had its baneful effect on physical symptoms. However, in this regard it is worthwhile to note that, this reporting of physical symptoms might be a mere reflection of their psychological instability and insecurity which might have resulted from their poor relationship with husband and dependency on their children. Even staying under the same roof with children alleviated physical symptoms to some extent probably due to division of labor.

SEXUAL DOMAIN: Poor QOL in this domain was found to be associated with younger age of the woman $\leq 50 \mathrm{yrs}$ and those who have attained menopause for $<5$ yrs of age. 
This may be because it was observed that in Indian rural perspective normally abstinence overrules the sexual behavior of men and women who are more than 50 years old. Deterioration of relationship with husband after menopause, monetary dependency on children, living under one roof with children and perception of one's health as average seemed to be the significant predictors of Poor QOL of sexual domain.

PSYCHOLOGICAL DOMAIN: Poor QOL was seen to be significantly associated with several factors like age of the woman $\leq 50$ years, time since menopause $\leq 5$ years. Apart from these, factors like deterioration of relationship with husband after menopause, not living together with the children under one roof, monetary dependency on children and perception of one's health as average, seemed to be significantly associated with poor psychological status of the woman. Interestingly, literate women suffered from psychological ill being as compared to illiterate women, probably because literate women are more aware of their needs and is the ones who feels deprived of all the good things in life.

QUALITY OF LIFE: Out of the 315 women 243 (77\%) had poor quality of life. By Bivariate analysis many variables were identified as predictors of poor Quality of life. Thus post menopause women who had poorer QOL were those whose age was more than 50 years [O.R. (C.I.) 4.06 (2.34-7.04)], who were more literate [O.R. (C.I.) 3.42 (1.98-5.9)], who were poorer, P.C.I $\leq$ Rs 1000 [O.R.(C.I.) 6.62 (3.58-12.26)], who had attained menopause for more than 5 years [O.R. (C.I.) 4.47 (2.56-7.78)], who never took regular exercise [O.R. (C.I.) 3.16 (1.73-5.74)], whose relationship with husband deteriorated after attaining menopause [O.R. (C.I.) 7.4 (4.06-13.52)], who did not live with their children [O.R. (C.I.) 5.95 (3.22-10.9)], who took monetary support from their children [O.R. (C.I.) 2.35 (1.45-3.81)] and those who felt that they had average health status [O.R. (C.I.) 3.53 (2.0-6.24)].

Then these variables already found significant were entered into a Multiple Logistic model (binary logistic: link function $=$ logit), The goodness of fit of the logistic regression model was assessed by Hosmer-Lemeshow statistics where $\mathrm{p}>.05$. The variables were entered by 'Backward LR' method after checking for the assumptions of independence and linearity. Multivariate analysis elicited that poor QOL was more among those who did not live with their own children [AOR ( $95 \%$ C.I.) 4.26 (2.1-8.6)], did not undertake regular exercise, [AOR (95\% C.I.) 2.88 (1.38-6.03)], were literate [AOR (95\% C.I.) $2.5(1.13-4.8)]$, were monetarily dependent on their children
[AOR (95\% C.I.) 2.5 (1.32-4.88)], and had attained menopause $>5$ years. [AOR (95\% C.I.) 4.82 (2.47-9.41)], while variables like perception of one's health as average, deterioration of relationship with husband after menopause, P.C.I and age of the woman $>50$ yrs lost their significance when entered into the model. Nagelkerke R square was 0.34 which means that $34 \%$ of the outcome could be explained by the variables included in the logistic regression model.

\section{DISCUSSION}

The primary aim of this study was to assess the QOL of post-menopausal women in rural India using the MENQOL and eliciting its determinants.

MENQOL questionnaire has been validated for use in postmenopausal women and has been used successfully by other studies too. ${ }^{6,7,8}$ Several studies indicated that QOL was impaired in menopausal women, ${ }^{6,7,8}$ because menopausal period is related with several physical and mental changes that may impact women's health outcomes. Thus in this study we have tried to evaluate the QOL of post-menopausal women both as specific and cumulative effect of the four major domains related to her health and wellbeing, namely vasomotor, physical, sexual and psychosocial.

In general in this study, being older, financial instability with P.C.I $\leq$ Rs 1000, having less physical activity, duration of menopause more than 5 years, income and marriage dissatisfaction not living together under one roof with own children and monetary dependency on children resulted in poorer menopause-specific QOL on many of the MENQOL domains. Previous studies that evaluated the association between menopausal symptoms and socio-demographic and lifestyle factors, reported that lower socio-economic status, education, length of menopause, physical activity, and age were related to QOL,, 8 the results were confirmed in this study too.

We found literacy had an important role to play in determining QOL of the women. In several studies, they concluded that women who had more than a high school educational level had experienced less disturbing and fewer symptoms during menopause. ${ }^{8,10,11}$ In two studies, it was shown that educational level had a significant effect on all QOL domains. ${ }^{89}$ where higher education rendered a better quality of life, in contrary to our study findings where literacy came out to be a significant predictor of poor QOL. However, in another study in which the overwhelming majority of the women had 12 or less years of 
education, it was demonstrated that those with a lower educational level had a low psychosocial score. ${ }^{12}$ In general; literacy was associated with better health, income and more opportunities in women's social life. This may be due to the fact that an educated woman was better informed, visited the healthcare personnel more and even had greater accessibility to basic amenities and therefore was more aware of her needs than her illiterate counterpart, which might have led to her increased reporting of symptoms that might have been very much ignored or even not realized by an uneducated woman.

We found that P.C.I $\leq$ Rs 1000 was associated with poor QOL in the vasomotor, physical and psychosocial domains. This result was confirmed in another study, by Fallahzadeh $\mathrm{H}$ where employment was shown to be associated with better QOL. Thus it might be concluded that poorer women visited the health services less and was more prone to ill health in the resource constraint settings of rural India.

In examining the quality of life scores according to length of menopause, menopausal duration less than 5 years had significant differences in psychosocial domain. The results were confirmed by other studies. ${ }^{9}$ A study by Cheny et al. in Chinese community reported that women in early years of post-menopause had lower QOL in vasomotor, psychosocial and physical domains. ${ }^{7}$ While in our study where women who had attained menopause for $<5 \mathrm{yrs}$ had poorer QOL in the sexual and psychosocial domain whereas greater physical symptoms were reported by women who had attained menopause for $>5$ yrs. Quality of life improved with performing exercise in the psychosocial, physical domains and also with the overall quality of life. This finding was compatible with results of Williams et al.'s study. ${ }^{7}$ Also Lorenzi et al. found that exercise activity had association with better QOL. ${ }^{11}$ Exercise had beneficial effects on women's mood, general wellbeing, and sleep disorders and even on cognitive functions. ${ }^{13}$ Women, who did not undertake exercise, had poor mental and physical health status. ${ }^{13}$ This finding was corroborated in our study also where women who did not undertake physical exercise in the form of brisk walking had poorer QOL when compared to women who regularly went for walking.

In a study in Iran, it was reported that there was a correlation between marital status and psychological and sexual QOL," while our study revealed that deterioration of relationship with husband after menopause had a detrimental effect on the QOL of post-menopausal women, not only in terms of her psychosocial wellbeing, but it also affected her sexual, physical and vasomotor domains, thus influencing the QOL of the woman in all the four major domains. However, it might be noted in this context that reporting of symptoms in all the domains might just be a mere reflection of the psychological instability the women faced after the deterioration of her relationship with husband post attainment of menopause.

Results of several studies showed that marriage satisfaction had association with QOL especially in psychological health status ${ }^{9}$ that is similar to our results where relationship with husband has got an important role to play. However comfort and happiness develops by marriage relations and losing or separating from husband has a big impact on the psychological health of menopausal women.

\section{LIMITATIONS}

Our study had some limitations. Women were asked to recall symptoms in the past four weeks. Although recall could be differentially biased based on different characteristics of women, we believe that this is a reasonable time frame for recall of many of our questions. Furthermore, since this is a cross-sectional study, we evaluated the association between factors and quality of life. We were unable to evaluate the impact of these factors on change in quality of life over time. Therefore case-control study or a cohort study would have yielded better and more convincing results.

\section{CONCLUSION}

In conclusion we would like to assert that post-menopausal women are those women who have just sprung from the spring board of middle age into the pool of old age. Therefore they form a special vulnerable group and it is high time that we think, work out and execute all feasible, appropriate and practical measures to give them a happy and joyful life till they die. With the increase of life expectancy greater thrust on their health care activities as well as social security mechanisms is the need of the hour. Our research work has very modestly tried to elicit some of the risk factors which affect the quality of life of these women beyond their reproductive years. These, we feel should be the basis of the IEC activities and health education on healthy lifestyle for promoting positive attitudes towards coping up with the stress of the post-menopausal phase. The problems of this special 
group must be dealt with efficiently at all levels individual, family and community with meaningful and relevant contributions of different stakeholders. Political will is a very useful and quick process of implementation of a plan and therefore separate policies need to be formulated which are more gender sensitive and should specially focus on this vulnerable group of post-menopausal women who fall in a transitional population between the reproductive age group and geriatric population.

\section{ACKNOWLEDGEMENTS}

Authors deeply acknowledge the post menopausal women of Singur block in Hooghly district of West-Bengal, India for their participation in the study. We would also like to thank the administrative authorities of Singur Block in Hooghly district for their support. The authors also acknowledge with gratitude director of All India Institute of Hygiene and Public Health for permitting them to conduct the study as well as ethical clearance.

\section{REFERENCES}

1. WHO-QOL BREF, Introduction, administration, scoring and generic version of assessment. Field Trial Version: (December 1996). Available on: http:// www.who.int/mental_health/media/en/76.pdf (Accessed: June 4, 2012).
2. Krishnakumar A. The old and the ignored. (2004). Frontline 21[19]:1-8. Avialable on: http://www.silverinnings.com/docs/Facts\%20n\%20lssues/ The\%20old\%20and\%20lgnored.pdf (Accessed: June 4, 2012).

3. National Program Implementation Plan $\mathrm{RCH}-\mathrm{II}$ Program Document. Available on: mohfw.nic.in/NRHM/RCH/guidelines/NPIP Rev III.pdf (Accessed: June 4, 2012).

4. Sagdeo MM, Arora D. Menopausal symptom: A Comparative Study between Rural and Urban India. JK Science Jan-March 2011; 13(1):23-6.

5. Blumel JE, Castelo-Branco C, Binfa L, Gramegna G, Tacla X, Aracena B, Cumsille MA, Sanjuan A. Quality of life after the menopause: A population study. Maturitas 2000 Jan 15;34(1):17-23.

6. Chen Y, Lin SQ, Wei Y, Gao HL, Wang SH, Wu ZL. Impact of menopause on quality of life in community-based women in China. Menopause 2008 Jan-Feb; 15(1):144-9.

7. Williams RE, Levine KB, Kalilani L, Lewis J, Clark RV. Menopausespecific questionnaire assessment in US population-based study shows negative impact on health-related quality of life. Maturitas. 2009 Feb 20;62(2):153-9.

8. Fallahzadeh $\mathrm{H}$. Quality of life after the menopause in Iran: A population study. Quality of Life Research 2010; 19(6):813-19.

9. Ehsanpour S, Eivazi M, Davazdah-Emami Sh. Quality of life after the menopause and its relation with marital status. Iranian Journal of Nursing and Midwifery Research 2007; 12(4):130-5.

10. Kakkar V, Kaur D, Chopra K, Kaur A, Kaur IP. Assessment of the variation in menopausal symptoms with age, education and working/non-working status in north-Indian sub population using menopause rating scale (MRS). Maturitas 2007 July 20;57(3):306-14.

11. de Lorenzi DR, Saciloto B, Artico GR, Fontana SK, ( 2009). Quality of life and related factors among climacteric women from south Brazil. Acta Med Port 2009 Jan-Feb; 22(1):51-8. [PubMed]

12. Li C, Borgfeldt C, Samsioe G, Lidfeldt J, Nerbrand C. Background factors influencing somatic and psychological symptoms in middle-age women with different hormonal status. A population-based study of Swedish women. Maturitas 2005 Nov-Dec; 52(3-4):306-18.

13. Villaverde-Gutiérrez C, Araújo E, Cruz F, Roa JM, Barbosa W, Ruíz-Villaverde G. Quality of life of rural menopausal women in response to a customized exercise programme. J AdvNurs 2006 April; 54(1):11-19. 